\title{
Chromosome Evolution in the Genus Partamona (Apidae: Meliponini), with Comments on B Chromosome Origin
}

\author{
Camila M. Novaes $^{\mathrm{a}}$ Marina S. Cunha ${ }^{\mathrm{a}}$ Hugo A. Werneck ${ }^{\mathrm{a}}$ \\ Anderson Fernandes $^{a}$ b Lucio A.O. Campos ${ }^{a}$ Denilce M. Lopes ${ }^{a}$ \\ aLaboratório de Citogenética de Insetos, Departamento de Biologia Geral, Universidade Federal de Viçosa, Viçosa, \\ Brazil; bepartamento de Ciências Biológicas, Universidade do Estado de Mato Grosso, Tangará da Serra, Brazil
}

\section{Keywords}

Banding patterns · Cytogenetic markers · Molecular phylogeny · Stingless bee · Supernumerary chromosomes

\begin{abstract}
The genus Partamona includes 33 species of stingless bees, of which 11 were studied cytogenetically. The main goal of this study was to propose a hypothesis about chromosomal evolution in Partamona by combining molecular and cytogenetic data. Cytogenetic analyses were performed on 3 Partamona species. In addition, the molecular phylogeny included mitochondrial sequences of 11 species. Although the diploid number was constant within the genus, $2 n=34$, $B$ chromosomes were reported in 7 species. Cytogenetic data showed karyotypic variations related to chromosome morphology and the amount and distribution of heterochromatin and repetitive DNA. The molecular phylogenetic reconstruction corroborated the monophyly of the genus and separated the 2 clades ( $A$ and $B$ ). This separation was also observed in the cytogenetic data, in which species within each clade shared most of the cytogenetic characteristics. Furthermore, our data suggested that the B chromosome in the genus Partamona likely originated from a common an-
\end{abstract}

cestor of the species that have it in clade B and, through interspecific hybridization, it appeared only in Partamona rustica from clade A. Based on the above, Partamona is an interesting genus for further investigations using molecular mapping of $B$ chromosomes as well as for broadening phylogenetic data.

(c) 2021 S. Karger AG, Basel

\section{Introduction}

Partamona Schwarz, 1939 is a stingless bee genus that is found from southern Mexico to southern Brazil, in both forest and urban environments [Pedro and Camargo, 2003]. These bees show great uniformity in their morphological features; therefore, the species have been identified by a combination of characteristics, such as the shape of teeth in the mandible, integument coloring, and the color of hair and wings [Pedro and Camargo, 2003]. The attributes of the nest entrance and nesting substrate have also been used to identify species in this genus [Camargo and Pedro, 2003].

The homogeneity reported for Partamona species is not restricted to morphological and behavioral traits, and karger@karger.com

www.karger.com $/ \mathrm{cgr}$

(C) 2021 S. Karger AG, Base

Karger"
Correspondence to:

Camila M. Novaes, camilamnovaes@gmail.com

Denilce M. Lopes, denilce.lopes@ufv.br 
the genus has frequently been described as a group of bees with a stable karyotype. The same diploid number $(2 \mathrm{n}=$ 34) was found in all studied Partamona species, P. ailyae, P. chapadicola, P. cupira, P. helleri, P. mulata, P. nhambiquara, $P$. peckolti, P. rustica, $P$. seridoensis, $P$. sooretamae, and P. vicina [Brito et al., 1997, 2003, 2005; Brito-Ribon et al., 1999; Marthe et al., 2010; Tosta et al., 2014; Gonçalves et al., 2020; Lopes et al., 2020]. Numerical changes in the karyotype have been reported regarding the presence of supernumerary chromosomes in P. cupira, P. helleri, and $P$. rustica, based on conventional cytogenetic analyses [Brito et al., 1997; Marthe et al., 2010; Martins et al., 2013, 2014; Tosta et al., 2014] as well as in P. gregaria, $P$. criptica, $P$. seridoensis, and $P$. chapadicola, using a molecular RAPD-SCAR marker [Correia et al., 2014; Tosta et al., 2014; Machado et al., 2016].

Despite the karyotype constancy, differences in the heterochromatin distribution, DAPI/CMA 3 , and $18 \mathrm{~S}$ rDNA patterns were observed among Partamona species [Brito et al., 2003, 2005; Marthe et al., 2010; Martins et al., 2014; Gonçalves et al., 2020; Lopes et al., 2020]. Differences in cytogenetic banding patterns have also been detected in other insect groups with the same diploid number [Gokhman and Kuznetsova, 2006], as well as in amphibians [Kasahara et al., 2003], fish [Vicari et al., 2008], plants [Hasterok et al., 2006], and mammals [Labaroni et al., 2014], contributing to taxonomic and systematic classification.

Chromosome analysis data, combined with DNA sequence information, have resulted in the establishment of patterns in chromosome evolution based on phylogenetic hypotheses within different taxonomic groups, such as ants [Cardoso et al., 2014, 2018; Micolino et al., 2019] and wasps [Paladino et al., 2015; Fusu, 2017; Menezes et al., 2017]. The available molecular phylogenetic inference regarding the genus Partamona is not well resolved and includes only a few species [Rasmussen and Cameron, 2010], most of which do not have available cytogenetic data. Therefore, there is a gap in knowledge regarding the phylogenetic evolutionary scenario in this genus, covering representatives of species with and without B chromosomes.

The goal of this study was to propose a phylogenetic hypothesis for chromosome evolution in the genus Partamona. For this, we surveyed several aspects of chromosome features in 13 Partamona species, 3 analyzed in the present paper, including chromosome number and morphology, presence/absence of $\mathrm{B}$ chromosomes, differential banding patterns (C- and DAPI/CMA 3 bandings), and mapping of $18 \mathrm{~S}$ rDNA clusters. The molecular phylogeny included 11 Partamona species, which allowed us to make new comments about the origin and evolution of the $\mathrm{B}$ chromosome in this genus.

\section{Materials and Methods}

\section{Biological Material}

Larvae of 3 Partamona species were collected to carry out the cytogenetic analyses: P. gregaria from Novo Progresso, Pará, Partamona auripennis from Redenção, Pará, and P. rustica from Lontra, Minas Gerais. Adult workers of 11 Partamona species were collected for molecular analyses (online suppl. Table S1; for all online suppl.material, seewww.karger.com/doi/10.1159/000520552). Adult individuals of Paratrigona sp. 1, Geotrigona sp. 1, Geotrigona sp. 2, Trigona sp. 1, Trigona sp. 2, and Melipona quadrifasciata were included as outgroups. Voucher specimens were deposited at the Laboratory of Molecular Biology of Insects of the Universidade Federal of Viçosa, Minas Gerais, Brazil.

\section{Cytogenetic Analyses}

Chromosomes were obtained from the brain ganglion of the larvae in the last instar stage [Imai et al., 1988]. After Giemsa staining, the chromosome number of each individual was determined, and chromosome morphology was defined according to the chromosome arm ratios proposed by Levan et al. [1964]. C-banding was performed according to Sumner [1972]. The metaphases were photographed under an Olympus BX-60 microscope coupled with a Q-Color3 camera.

Fluorescence in situ hybridization (FISH) was performed according to Pinkel et al. [1986]. The $18 \mathrm{~S}$ rDNA probe was obtained by PCR amplification using 18S F (5'-GTCATATGCTTGTCTCAAAGA- $\left.3^{\prime}\right)$ and $18 \mathrm{~S}$ R ( $3^{\prime}$-TCTAATTTTTCAAAGTAAACGC-5') primers, labeled with digoxigenin-11-dUTP (Roche Applied Science), and the signal was detected with anti-digoxigeninrhodamine (Roche Applied Science). Staining with chromomycin $\mathrm{A}_{3} / 4^{\prime}$,6-diamidino-2-phenylindole ( $\mathrm{CMA}_{3} / \mathrm{DAPI}$ ) fluorochromes was conducted following the methods described by Schweizer [1980]. The results of the fluorescence techniques were photographed with an Olympus BX-53 epifluorescence photomicroscope coupled to an Olympus XM10 camera and assembled using the Adobe Photoshop ${ }^{\circledR}$ 21.1.1 image-editing program. The idiograms of the karyotypes were drawn using Easy Idio software [Diniz and Melo, 2006].

\section{Molecular Analyses}

Total DNA was extracted according to the method described by Waldschmidt et al. [1997]. Partial sequences of the cytochrome oxidase subunit $1(C O I)$ and cytochrome $\mathrm{B}(\mathrm{Cyt} B)$ genes were amplified using the COIdegF(TAAACTTCWGGATGWCCAAAAAATCA) and COIdegR (TATCWACHAATCATAAAAATMTTGG) primers and CytbF (TCGTTTAATTCAYATAAATGGAGC) and CytbR (ATTACWCCTCCTAATTTATTWGGAAT) primers, respectively [Batalha-Filho et al., 2010]. Sequences were deposited in GenBank with accession numbers OK636162-OK636200.

Consensus sequences from the forward and reverse strands of each sample were assembled using the CodonCode Aligner package v.5 (Copyright, 2002-2015 CodonCode Corporation). The sequences of each gene fragment were separately aligned in the pro- 


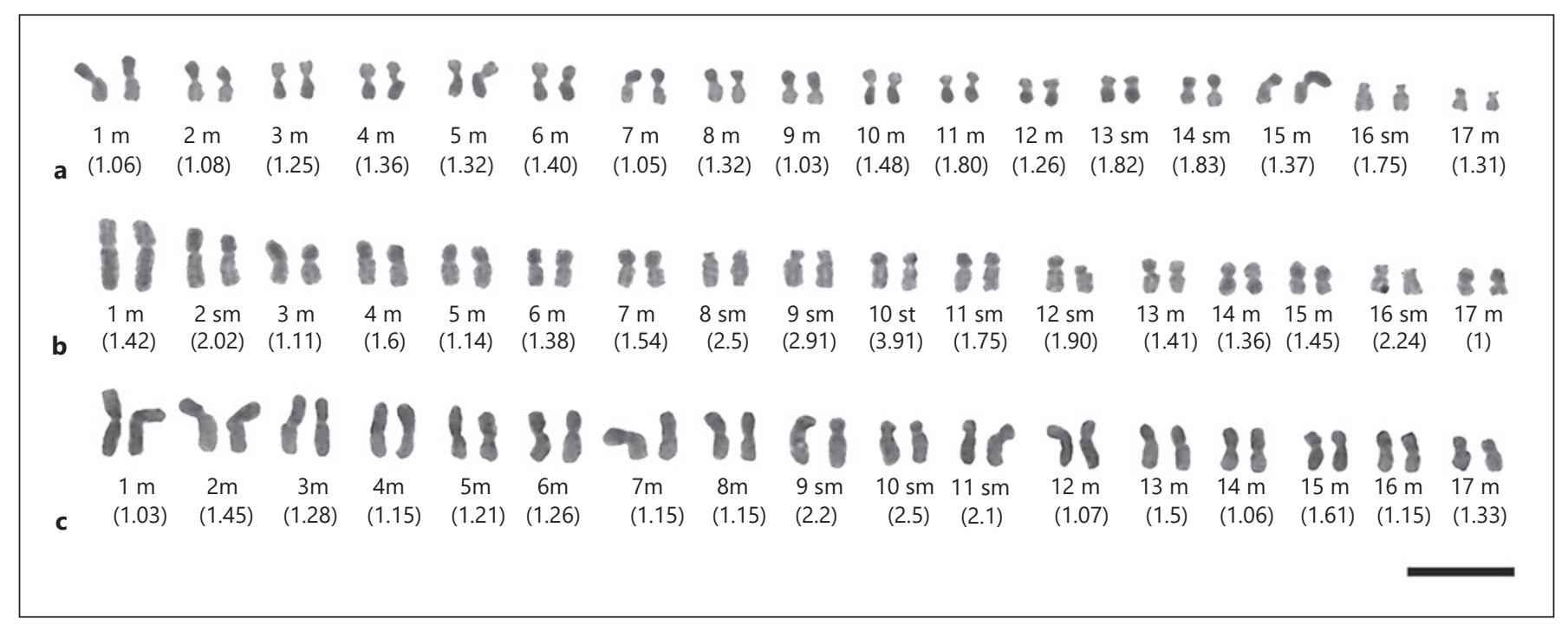

Fig. 1. Giemsa-stained karyotypes of the Partamona species. a P. gregaria. b P. auripennis. c P. rustica. Chromosome arm ratios are shown in parentheses. Scale bar, $10 \mu \mathrm{m}$.

gram Mega v6.06 [Tamura et al., 2013] using the MUSCLE method, and the data were concatenated into a single matrix using the SequenceMatrix program [Vaidya et al., 2011].

Bayesian inference was performed online using the CIPRES Science Gateway server [Miller et al., 2010] with the program MrBayes v.3.2.1 [Ronquist et al., 2012]. Two independent runs were used, each with 4 Monte Carlo Markov Chain (MCMC) replications. For this, the mixed model was implemented [Ronquist and Huelsenbeck, 2003] with an invariant ratio and Gamma correction for the 2 gene fragments. For the tree generated from the concatenated data, 12,000,000 generations of the MCMC were used with trees sampled every 1,000 generations. The convergence of the Markov chains was verified using the program Tracer v.1.5 [Rambaut and Drummond, 2009]. Twenty-five percent of the initial MCMC generations were excluded, and the remainder was used to calculate a consensus tree. The frequency of each branch in the majority consensus represented the value of the PP (posterior probability) of the Bayesian formula. The tree resulting from the analysis was edited in FigTree v. 1.3.1 [Rambaut, 2009].

\section{Results}

Karyotype Analyses

The diploid number determined for the 3 analyzed species was $2 \mathrm{n}=34$, without the presence of B chromosomes. Male individuals $(\mathrm{n}=17)$ were found in P. gregaria. The karyotype formulae were $2 \mathrm{k}=28 \mathrm{~m}+6 \mathrm{sm}$ in $P$. gregaria, $2 \mathrm{k}=20 \mathrm{~m}+12 \mathrm{sm}+2 \mathrm{st}$ in $P$. auripennis, and $2 \mathrm{k}=28 \mathrm{~m}+6 \mathrm{sm}$ in $P$. rustica (Fig. 1). In P. gregaria, the heterochromatin was restricted to the centromeric and pericentromeric regions (Fig. 2a), whereas it was ob- served along the short arm of all chromosomes of $P$. auripennis (Fig. 2b). In P. rustica, heterochromatin was distributed in the centromeric and pericentromeric regions, as well as along one chromosome arm, with less intense staining (Fig. 2c).

$18 \mathrm{~S}$ rDNA clusters were observed in 6 chromosomes of $P$. gregaria (Fig. 2d), 2 chromosomes of $P$. auripennis (Fig. 2e), and 4 chromosomes of $P$. rustica (Fig. 2f). In addition, $\mathrm{CMA}_{3}{ }^{+}$markings were identified in 6 chromosomes of $P$. gregaria, 2 chromosomes of $P$. auripennis, and 4 chromosomes of $P$. rustica, whereas $\mathrm{DAPI}^{+}$regions overlapped with the heterochromatin regions (online suppl. Fig. S1).

An idiogram of the species' karyotypes was drawn to facilitate visualization of cytogenetic patterns (Fig. 3a). Although $P$. auripennis was not sampled for molecular analysis, its cytogenetic patterns are characteristic of clade A.

\section{Molecular Analyses}

The mean partial sequence sizes of the $C O I$ and $C y t B$ genes were 593 and 598 bp, respectively. Phylogenetic reconstruction, based on the COI and $C y t B$ sequences, confirmed the monophyly of the genus Partamona (online suppl. Fig. S2) and showed the division into 2 clades (A and $\mathrm{B}$ ). Clade $\mathrm{A}$ was formed by the species $P$. ailyae, $P$. rustica, $P$. mulata, $P$. testacea, and $P$. vicina, and clade B included the species $P$. chapadicola, $P$. seridoensis, $P$. cupira, P. helleri, P. gregaria, and P. nhambiquara (Fig. 3b). 

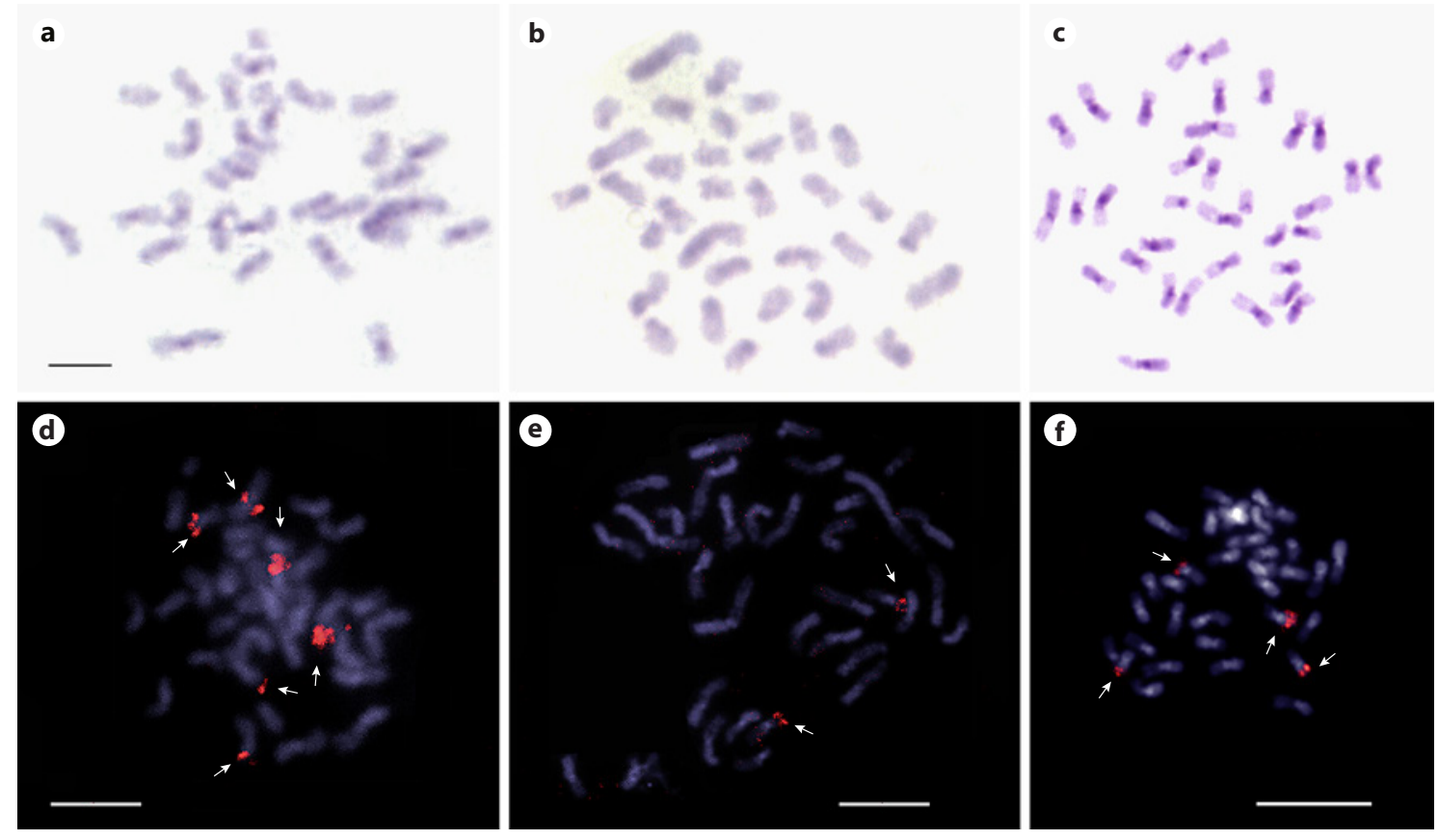

Fig. 2. Partamona metaphases subjected to C-banding and FISH using $18 \mathrm{~S}$ rDNA. a, d $P$. gregaria. b, e $P$. auripennis. c, f $P$. rustica. The arrows indicate hybridization signals. Scale bars, $10 \mu \mathrm{m}(\mathbf{a}-\mathbf{c})$ and $5 \mu \mathrm{m}(\mathbf{d}-\mathbf{f})$.

\section{Discussion}

Cytogenetic information available for Partamona currently comprises data of 13 karyotyped species out of the 33 species described in this genus. The diploid number of $P$. gregaria, $P$. auripennis, and $P$. rustica $(2 \mathrm{n}=34)$ was similar to the other species in this genus (Table 1), as well as in the closely related Meliponini [reviewed in Cunha et al., 2021a], confirming the chromosome number conservatism in this group of bees. On the other hand, variations in chromosome morphology among species are related to cytogenetic rearrangements that do not alter the diploid number.

The minimum interaction theory has been proposed to explain karyotype evolution in the Hymenoptera order [Imai et al., 1988, 1994; Hoshiba and Imai, 1993]. According to this theory, chromosomes pass through fission events that increase the number of smaller chromosomes, with a concomitant increase in heterochromatin, which would lead to a decrease in deleterious interactions during the cell cycle. Considering that Partamona species and closely related Meliponini genera share the same diploid number $(2 \mathrm{n}=34)$, fission events and, consequently, increases in the number of chromosomes would not be the main model of karyotype evolution as predicted by the minimum interaction theory. Recently, alternative hypotheses have proposed a handful of rearrangements to explain karyotype evolution in the Meliponini tribe [Tavares et al., 2017; Travenzoli et al., 2019; Cunha et al., 2021b].

Additionally, the C-banding, $\mathrm{CMA}_{3}{ }^{+}$, and $18 \mathrm{~S}$ rDNA markings revealed other differences in Partamona karyotypes, showing that they are not homogeneous in their chromatin composition (Table 1). These differences allowed the separation of the 2 clades, which species shared most of the cytogenetic characteristics, suggesting that they may have followed different evolutionary pathways. This division corroborated the molecular phylogeny (Fig. 3).

Phylogenetic reconstruction based on $C O I$ and $C y t B$ sequences confirmed the monophyly of the genus Partamona [Camargo and Pedro, 2003; Rasmussen and Cameron, 2010]. However, the phylogenetic relationships inferred by molecular data differed from those based on morphological data and did not corroborate the previous morphological groups [Camargo and Pedro, 2003; Pedro and Camargo, 2003]. We associated the 2 clades observed in the molecular phylogeny with the available cytogenetic literature (Table 2) to comment on the origin and evolution of $\mathrm{B}$ chromosomes in this genus. 
a
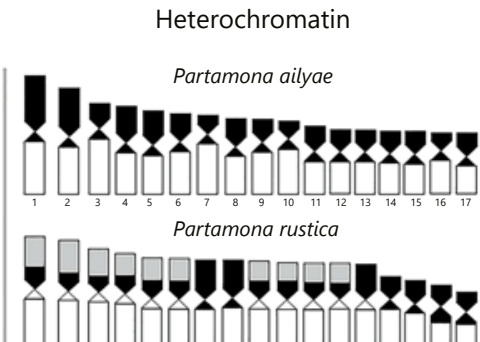

Partamona mulata

A

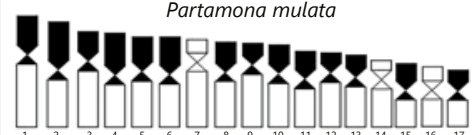

Partamona vicina

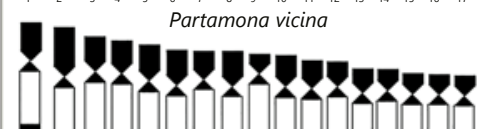

Partamona auripennis

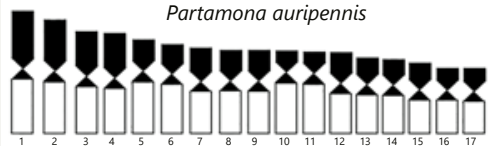

Partamona chapadicola

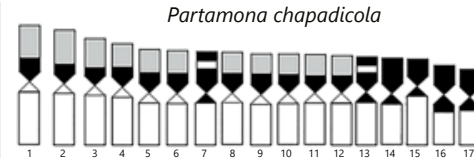

Partamona seridoensis

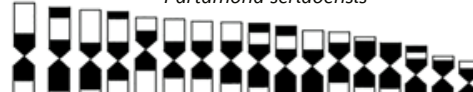

Partamona helleri

B

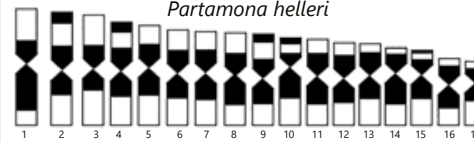

Partamona gregaria

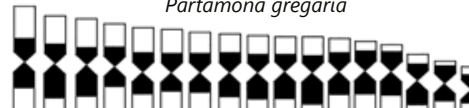

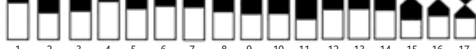

Partamona nhambiquara

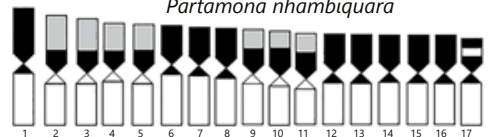

$\mathrm{CMA}_{3} / 18 \mathrm{~S}$
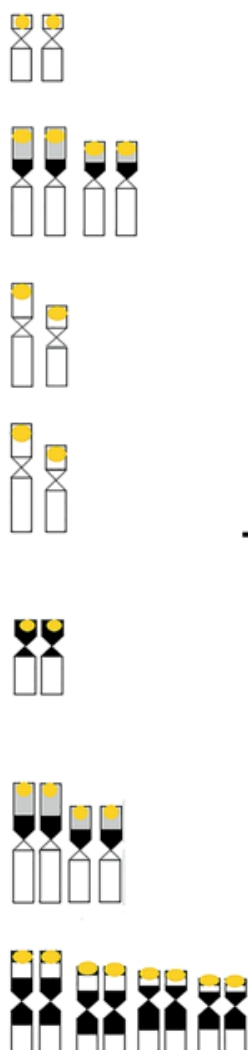

b

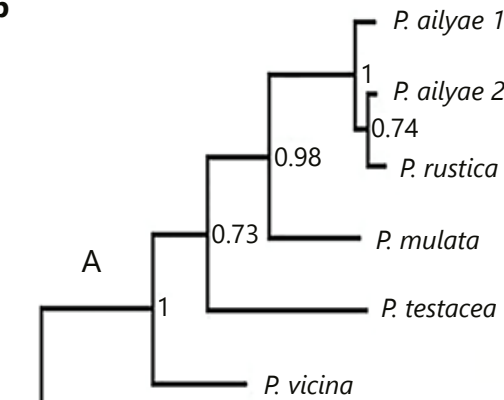

P.ch

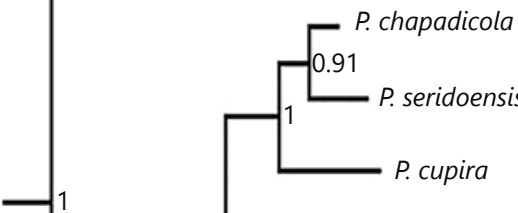

B

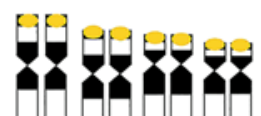

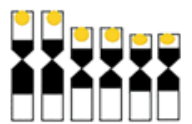

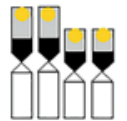

Fig. 3. a Idiograms of the heterochromatin and $\mathrm{CMA}_{3}{ }^{+} / 18 \mathrm{~S}$ rDNA distribution patterns in Partamona. b Concatenated Bayesian phylogeny of the $C O I$ and $C y t B$ genes showing the division of Partamona species into clades $\mathrm{A}$ and $\mathrm{B}$.

The supernumerary chromosomes are regarded as parasitic elements that accumulate in the host genome, regardless of possible negative impacts on fitness [reviewed in Camacho, 2005]. They do not follow mendelian segregation, and there are 2 possible scenarios for their origin: (1) intraspecific origin from the A chromosome complement of the host species, or (2) interspecific origin as a result of hybridization of different species [Camacho 
Table 1. Cytogenetic data on diploid number, heterochromatin patterns, and number of chromosomes marked with $\mathrm{CMA}_{3}$ and $18 \mathrm{~S}$ rDNA probe available for the genus Partamona

\begin{tabular}{|c|c|c|c|c|c|}
\hline Species & $2 n$ & Heterochromatin distribution & $\begin{array}{l}\mathrm{CMA}_{3}^{+} \\
\text {chromosomes, } \\
n\end{array}$ & $\begin{array}{l}18 \text { S carrying } \\
\text { chromosomes, } \\
n\end{array}$ & References \\
\hline P. ailyae & 34 & Along one chromosomal arm & 8 & 2 & $\begin{array}{l}\text { Brito-Ribon et al., 1999; } \\
\text { Gonçalves et al., } 2020\end{array}$ \\
\hline P. helleri & 34 & $\begin{array}{l}\text { Centromeric and pericentromeric regions, } \\
\text { and a few terminal blocks }\end{array}$ & 5 to 12 & 6 to 8 & $\begin{array}{l}\text { Brito et al., 1997, 2005; Martins } \\
\text { et al., 2009, 2013; Gonçalves et } \\
\text { al., } 2020\end{array}$ \\
\hline P. mulata & 34 & Along one chromosomal arm & 2 & - & Brito-Ribon et al., 1999 \\
\hline P. rustica & 34 & $\begin{array}{l}\text { Along one chromosomal arm, with } \\
\text { chromosomes showing } 3 \text { color patterns }\end{array}$ & 4 & 4 & Present study \\
\hline \multicolumn{6}{|l|}{ Nigrior group } \\
\hline P. auripennis & 34 & Along one chromosomal arm & 2 & 2 & Present study \\
\hline P. chapadicola & 34 & $\begin{array}{l}\text { Along one chromosomal arm, with } \\
\text { chromosomes showing } 3 \text { color patterns }\end{array}$ & 4 & 6 & Lopes et al., 2020 \\
\hline P. seridoensis & 34 & $\begin{array}{l}\text { Blocks mainly in the pericentromeric } \\
\text { regions, and a few terminal blocks }\end{array}$ & 8 & 7 & Brito et al., 2005 \\
\hline \multicolumn{6}{|l|}{ Musarum group } \\
\hline P. gregaria & 34 & Centromeric and pericentromeric regions & 6 & 6 & Present study \\
\hline
\end{tabular}

The species were separated into groups based on the morphological proposal of Pedro and Camargo [2003].

et al., 2000]. Due to a lack of homology with the A complement in P. helleri [Martins et al., 2013] and the presence of the same genetic marker (RAPD-SCAR) in other Partamona species [Correia et al., 2014; Machado et al., 2016], the $B$ chromosome in this genus is believed to have been recently transferred through several interspecific hybridizations [Tosta et al., 2014] or, alternatively, originated in the common ancestor of the species that share the homology of the B RAPD-SCAR sequence [Machado et al., 2016].

Chromosome Evolution in Partamona
Our phylogenetic analyses allowed us to shed some light on this issue. Within clade A, only P. rustica had B chromosomes, whereas most species of clade B had these extra elements, except $P$. nhambiquara (Table 2). Therefore, not all species with B chromosomes group together in the same clade, which does not corroborate the common ancestor hypothesis [Machado et al., 2016]. Instead of several hybridizations [Tosta et al., 2014], one interspecific hybridization could explain its presence only in $P$. rustica from clade A, which shares the same RAPD-SCAR 
Table 2. B chromosome information for the Partamona species analyzed in the molecular phylogeny

\begin{tabular}{|c|c|c|c|}
\hline Clade & Species & B chromosomes ${ }^{\mathrm{a}}$ & References \\
\hline \multirow[t]{4}{*}{ A } & P. ailyae & $\begin{array}{l}\mathrm{B}^{-} \text {cytogenetic } \\
\mathrm{B}^{-} \text {SCAR sequence }\end{array}$ & $\begin{array}{l}\text { Brito-Ribon et al., } 1999 \\
\text { Correia et al., 2014; Machado et al., } 2016\end{array}$ \\
\hline & P. rustica & $\begin{array}{l}\mathrm{B}^{+} \text {cytogenetic } \\
\mathrm{B}^{+} \text {SCAR sequence }\end{array}$ & Correia et al., 2014; Tosta et al., 2014; Machado et al., 2016 \\
\hline & P. mulata & $\begin{array}{l}B^{-} \text {cytogenetic } \\
B^{-} \text {SCAR sequence }\end{array}$ & $\begin{array}{l}\text { Brito-Ribon et al., } 1999 \\
\text { Correia et al., 2014; Machado et al., } 2016\end{array}$ \\
\hline & P. vicina & $\begin{array}{l}B^{-} \text {cytogenetic } \\
B^{-} \text {SCAR sequence }\end{array}$ & $\begin{array}{l}\text { Brito-Ribon et al., } 1999 \\
\text { Correia et al., 2014; Machado et al., } 2016\end{array}$ \\
\hline \multirow[t]{6}{*}{ B } & P. nhambiquara & $\begin{array}{l}B^{-} \text {cytogenetic } \\
B^{-} \text {SCAR sequence }\end{array}$ & $\begin{array}{l}\text { Lopes et al., } 2020 \\
\text { Correia et al., } 2014\end{array}$ \\
\hline & P. gregaria & $\begin{array}{l}B^{-} \text {cytogenetic } \\
B^{+} \text {SCAR sequence }\end{array}$ & $\begin{array}{l}\text { Present study } \\
\text { Correia et al., 2014; Machado et al., } 2016\end{array}$ \\
\hline & P. chapadicola & $\begin{array}{l}B^{-} \text {cytogenetic } \\
B^{+} \text {SCAR sequence }\end{array}$ & $\begin{array}{l}\text { Lopes et al., } 2020 \\
\text { Correia et al., 2014; Machado et al., } 2016\end{array}$ \\
\hline & P. seridoensis & $\begin{array}{l}B^{-} \text {cytogenetic } \\
B^{+} \text {SCAR sequence }\end{array}$ & $\begin{array}{l}\text { Brito et al., } 2005 \\
\text { Correia et al., 2014; Machado et al., } 2016\end{array}$ \\
\hline & P. cupira & $\begin{array}{l}\mathrm{B}^{+} \text {cytogenetic } \\
\mathrm{B}^{+} \text {SCAR sequence }\end{array}$ & $\begin{array}{l}\text { Marthe et al., } 2010 \\
\text { Correia et al., 2014; Tosta et al., 2014; Machado et al., } 2016\end{array}$ \\
\hline & P. helleri & $\begin{array}{l}\mathrm{B}^{+} \text {cytogenetic } \\
\mathrm{B}^{+} \text {SCAR sequence }\end{array}$ & Correia et al., 2014; Tosta et al., 2014; Machado et al., 2016 \\
\hline
\end{tabular}

a Presence $\left(\mathrm{B}^{+}\right)$or absence $\left(\mathrm{B}^{-}\right)$of $\mathrm{B}$ chromosomes based on cytogenetic or RAPD-SCAR sequence data.

sequence with clade B species. The overall cytogenetic data of this species also share some resemblance with clade B (Fig. 3a). On the other hand, the origin of the supernumerary chromosomes in clade B can be traced to the common ancestor of the species, except for P. nhambiquara which do not have B chromosomes. Further investigations are needed to clarify the polytomy between $P$. gregaria and P. nhambiquara, and to confirm the plesiomorphic condition of the absence of $\mathrm{B}$ chromosomes in this clade.

We observed a discrepancy regarding the presence of B chromosomes in some Partamona species between the cytogenetic and RAPD-SCAR data (Table 2). The nonmendelian segregation of the $\mathrm{B}$ chromosomes and their presence in low numbers in most of the species' populations could explain this discrepancy of $\mathrm{B}^{-}$with conventional cytogenetics and $\mathrm{B}^{+}$when we expand the sampling with the RAPD-SCAR sequence. Since this molecular marker was originally designed for $P$. helleri, further cytogenetic analyses should investigate its cytological presence in other Partamona species to rule out the hypoth- esis that it is present in the A chromosomes of some Blacking species.

Bee chromosome evolution has traditionally been considered stable because of the apparent high karyotype conservatism of several taxa. However, the presence of variation, particularly structural alterations in repetitive DNA distribution patterns, has challenged this idea. Unlike the morphological and behavioral characteristics that are not very informative in systematic studies in the genus Partamona, the cytogenetic data are congruent with the molecular information, thus providing potential sources of phylogenetic information for this group of bees.

\section{Acknowledgments}

The authors wish to thank Sílvia Regina de Menezes Pedro (Universidade de São Paulo, Ribeirão Preto, Brazil) for Partamona species identification. 


\section{Statement of Ethics}

Ethical approval is not required for this type of research.

\section{Conflict of Interest Statement}

The authors declare that they have no conflict of interest.

\section{Funding Sources}

The study was funded by Conselho Nacional de Desenvolvimento Científico e Tecnológico (CNPq), Coordenação de Aperfeiçoamento de Pessoal de Nível Superior (CAPES), and Fundação de Amparo à Pesquisa do Estado de Minas Gerais (FAPEMIG).

\section{Author Contributions}

Study conception and design: C.M.N., A.F., and D.M.L. Data collection and analyses: C.M.N., M.S.C., A.F., and H.A.W. Supervision: L.A.O.C. and D.M.L. Literature review and first draft of the manuscript: C.M.N. and M.S.C. All authors commented on previous versions and approved the final manuscript.

\section{Data Availability Statement}

All data generated or analyzed during this study are included in this article or its supplementary material files. Further inquiries can be directed to the corresponding authors.

\section{References}

Batalha-Filho $\mathrm{H}$, Waldschmidt AM, Campos LAO, Tavares MG, Fernandes-Salomão TM. Phylogeography and historical demography of the neotropical stingless bee Melipona quadrifasciata (Hymenoptera, Apidae): Incongruence between morphology and mitochondrial DNA. Apidologie. 2010;41:534-47.

Brito RM, Costa MA, Pompolo SG. Characterization and distribution of supernumerary chromosomes in 23 colonies of Partamona helleri (Hymenoptera, Apidae, Meliponinae). Braz J Genet. 1997;20:185-8.

Brito RM, Caixeiro APA, Pompolo SG, Azevedo GG. Cytogenetic data of Partamona peckolti (Hymenoptera, Apidae, Meliponini) by $\mathrm{C}$ banding and fluorochrome staining with DA/ CMA3 and DA/DAPI. Genet Mol Biol. 2003; 26:53-7.

Brito RM, Pompolo SG, Magalhães MFM, Barros EG, Hojo ETS. Cytogenetic characterization of two Partamona species (Hymenoptera, Apinae, Meliponini) by fluorochrome staining and localization of $18 \mathrm{~S}$ rDNA clusters by FISH. Cytologia. 2005;70:373-80.

Brito-Ribon RM, Miyazawa CS, Pompolo SG. First karyotype characterization of four species of Partamona (Friese, 1980) (Hymenoptera, Apidae, Meliponini) in Mato Grosso State - Brazil. Cytobios. 1999;100:19-26.

Camacho JPM. B chromosomes. In: Gregory TR, editor. The evolution of the genome. Academic Press; 2005. p. 223-86.

Camacho JP, Sharbel TF, Beukeboom LW. Bchromosome evolution. Philos Trans R Soc Lond B Biol Sci. 2000;355:163-78.

Camargo JMF, Pedro SEM. Meliponini neotropicais: o gênero Partamona Schwarz, 1939 (Hymenoptera, Apidae, Apinae) - bionomia e biogeografia. Rev Bras Entomol. 2003;47: $311-72$.
Cardoso DC, Pompolo SG, Cristiano MP, Tavares MG. The role of fusion in ant chromosome evolution: insights from cytogenetic analysis using a molecular phylogenetic approach in the genus Mycetophylax. PLoS One. 2014;9: e87473.

Cardoso DC, Heinze J, Moura MN, Cristiano MP. Chromosomal variation among populations of a fungus-farming ant: implications for karyotype evolution and potential restriction to gene flow. BMC Evol Biol. 2018;18:146.

Correia AM, Fernandes A, Campos LAO, Lopes DM. Análise da presença do marcador SCAR associado ao cromossomo B em espécies de abelha sem ferrão do gênero Partamona. Rev Bras Biocienc. 2014;12:196-200.

Cunha MS, Cardoso DC, Cristiano MP, Campos LAO, Lopes DM. The Bee Chromosome Database (Hymenoptera: Apidae). Apidologie. 2021a;52:493-502.

Cunha MS, Soares FAF, Clarindo WR, Campos LAO, Lopes DM. Robertsonian rearrangements in Neotropical Meliponini karyotype evolution (Hymenoptera: Apidae: Meliponini). Insect Mol Biol. 2021b;30:379-89.

Diniz D, Melo PX. Easy Idio, version 1.0. 2006.

Fusu L. An integrative taxonomic study of European Eupelmus (Macroneura) (Hymenoptera: Chalcidoidea: Eupelmidae), with a molecular and cytogenetic analysis of Eupelmus (Macroneura) vesicularis: several species hiding under one name for 240 years. Zool J Linn Soc. 2017;181:519-603.

Gokhman VE, Kuznetsova VG. Comparative insect karyology: current state and applications. Entmol Rev. 2006;86:352-68.

Gonçalves GC, Dalbosco AM, Barth A, Miranda EA, Costa MA. Comparative cytogenetic analysis of three species of the genus Partamona (Apidae, Meliponini). Apidologie. 2020; 52:80-8.
Hasterok R, Wolny E, Hosiawa M, Kowalczyk M, Kulak-Ksiazczyk S, Ksiazczyk T, et al. Comparative analysis of rDNA distribution in chromosomes of various species of Brassicaceae. Ann Bot. 2006;97:205-16.

Hoshiba H, Imai H. Chromosome evolution of bees and wasps (Hymenoptera, Apocrita) on the basis of C-banding pattern analyses. Jpn J Entomol. 1993;61:465-92.

Imai HT, Taylor RW, Crosland MW, Crozier RH. Modes of spontaneous chromosomal mutation and karyotype evolution in ants with reference to the minimum interaction hypothesis. Jpn J Genet. 1988;63:159-85.

Imai HT, Brown WLJ, Kubota M, Yong HS, Tho YP. Chromosome observations on tropical ants from western Malaysia. Annu Rep Natl Inst Genet. 1994;34:66-9.

Kasahara S, Zampieri Silva AP, Gruber SL, Haddad CF. Comparative cytogenetic analysis on four tree frog species (Anura, Hylidae, Hylinae) from Brazil. Cytogenet Genome Res. 2003;103:155-62.

Labaroni CA, Malleret MM, Novillo A, Ojeda A Rodriguez D, Cuello P, et al. Karyotypic variation in the Andean rodent Phyllotis xanthopygus (Waterhouse, 1837) (Rodentia, Cricetidae, Sigmodontinae). Comp Cytogenet. 2014; 8:369-81.

Levan A, Fredga K, Sandberg AA. Nomenclature for centromeric position on chromosomes. Hereditas. 1964;52:201-20.

Lopes DM, Travenzoli NM, Fernandes A, Campos LAO. Different levels of chromatin condensation in Partamona chapadicola and Partamona nhambiquara (Hymenoptera, Apidae). Cytogenet Genome Res. 2020;160:20613. 
Machado DP, Miranda EA, Dessi MC, Sabadini CP, Del Lama MA. Occurrence and origin of supernumerary chromosomes in Partamona (Hymenoptera: Apidae: Meliponini). Cytogenet Genome Res. 2016;150:68-75.

Marthe JB, Pompolo SG, Campos LAO, Salomão TMF, Tavares MG. Cytogenetic characterization of Partamona cupira (Hymenoptera, Apidae) by fluorochromes. Genet Mol Biol. 2010;33:253-5.

Martins CC, Duarte OMP, Waldschmidt AM, Alves RMO, Costa MA. New occurrence of B chromosomes in Partamona helleri (Friese, 1900) (Hymenoptera, Meliponini). Genet Mol Biol. 2009;32:782-5.

Martins CCC, Diniz D, Sobrinho-Scudeler PE, Foresti F, Campos LAO, Costa MA. Investigation of Partamona helleri (Apidae, Meliponini) B chromosome origin. An approach by microdissection and whole chromosome painting. Apidologie. 2013;44:75-81.

Martins CCC, Waldschmidt AM, Costa MA. Unprecedented record of ten novel B chromosomes in the stingless bee Partamona helleri (Apidae, Meliponini). Apidologie. 2014;45: 431-9.

Menezes RST, Brady SG, Carvalho AF, Del Lama MA, Costa MA. The roles of barriers, refugia, and chromosomal clines underlying diversification in Atlantic Forest social wasps. Sci Rep. 2017;7:7689.

Micolino R, Cristiano MP, Travenzoli NM, Lopes DM, Cardoso DC. Chromosomal dynamics in space and time: evolutionary history of $\mathrm{My}$ cetophylax ants across past climatic changes in the Brazilian Atlantic coast. Sci Rep. 2019; 9:18800.
Miller MA, Pfeiffer W, Schwartz T. Creating the CIPRES Science Gateway for inference of large phylogenetic trees. In. Proceedings of the Gateway Computing Environments Workshop (GCE). New Orleans, LA; 2010.

Paladino LC, Muntaabski I, Lanzavecchia S, Bagousse-Pinguet $\mathrm{YL}$, Viscarret $\mathrm{M}$, Juri $\mathrm{M}$, et al. Complementary sex determination in the parasitic wasp Diachasmimorpha longicaudata. PLoS One. 2015;10:e0119619.

Pedro SEM, Camargo JMF. Meliponini neotropicais: o gênero Partamona Schwarz, 1939 (Hymenoptera, Apidae). Rev Bras Entomol. 2003;47:1-117.

Pinkel D, Straume T, Gray JW. Cytogenetic analysis using quantitative, high-sensitivity, fluorescence hybridization. Proc Natl Acad Sci U S A. 1986;83:2934-8.

Rambaut A: FigTree, ver. 1.3.1. (2009) [Online]. Available from: http://tree.bio.ed.ac.uk/software/figtree/. Last accessed 02/02/2017.

Rambaut A, Drummond A: Tracer, Version 1.5. (2009). http: //tree.bio.ed.ac.uk/software/ tracer/. Last accessed 02/02/2017.

Rasmussen C, Cameron SA. Global stingless bee phylogeny supports ancient divergence, vicariance, and long distance dispersal. Biol Linn Soc. 2010;99:206-32.

Ronquist F, Huelsenbeck JP. MrBayes 3: Bayesian phylogenetic inference under mixed models. Bioinformatics. 2003;19:1572-4.

Ronquist F, Klopfstein S, Vilhelmsen L, Schulmeister S, Murray DL, Rasnitsyn AP. A totalevidence approach to dating with fossils, applied to the early radiation of the Hymenoptera. Syst Biol. 2012;61:973-99.

Schweizer D. Simultaneous fluorescent staining of $\mathrm{R}$ bands and specific heterochromatic regions (DA-DAPI bands) in human chromosomes. Cytogenet Cell Genet. 1980;27:190-3.
Sumner AT. A simple technique for demonstrating centromeric heterochromatin. Exp Cell Res. 1972;75:304-6.

Tamura Y, Harada Y, Nishikawa SI, Yamano K, Kamiya M, Shiota T, et al. Tam41 is a CDPdiacylglycerol synthase required for cardiolipin biosynthesis in mitochondria. Cell Metab. 2013;17:709-18.

Tavares MG, Lopes DM, Campos LAO. An overview of cytogenetics of the tribe Meliponini (Hymenoptera: Apidae). Genetica. 2017;145: 241-58.

Tosta VC, Marthe JB, Tavares MG, FernandesSalomão TM, Pompolo SG, Recco-Pimentel $\mathrm{SM}$, et al. Possible introgression of $\mathrm{B}$ chromosomes between bee species (genus Partamona). Cytogenet Genome Res. 2014;144:220-6.

Travenzoli NM, Cardoso DC, Werneck HA, Fernandes-Salomão TM, Tavares MG, Lopes DM. The evolution of haploid chromosome numbers in Meliponini. PloS One. 2019;14: e0224463.

Vaidya G, Lohman DJ, Meier R. SequenceMatrix: concatenation software for the fast assembly of multigene datasets with character set and codon information. Cladistics. 2011;27:17180.

Vicari MR, Noleto RB, Artoni RF, Moreira-Filho O, Bertollo LAC. Comparative cytogenetics among species of the Astyanax scabripinnis complex. Evolutionary and biogeographical inferences. Genet Mol Biol. 2008;31:173-9.

Waldschmidt AM, Fernandes-Salomão TM, Barros EG, Campos LAO. Extraction of genomic DNA from Melipona quadrifasciata (Hymenoptera: Apidae, Meliponae). Braz J Genet. 1997;20:421-3. 